\title{
Autosomal dominant primary hypomagnesemia with hypocalciuria
}

INSERM

\section{Source}

INSERM. (1999). Orphanet: an online rare disease and orphan drug data base. Autosomal dominant primary hypomagnesemia with hypocalciuria. ORPHA:34528

A mild form of familial primary hypomagnesemia (FPH), characterized by extreme weakness, tetany and convulsions. Secondary disturbances in calcium excretion are observed. 